\title{
Simple and Inexpensive Live Trap for Capturing Fossorial Small Mammals. Mediterranean Vole: An Example
}

\author{
PROSTA I TANIA ZYYWOŁOWKA NA RYJACE MA£E SSAKI
}

R. C. SORIGUER, M. LOPEZ ${ }^{1}$ \& ZAFRA M. ${ }^{2}$

\begin{abstract}
Soriguer R. C., Lopez M. \& Zafra M., 1984: Simple and inexpensive live trap for capturing fossorial small mammals. Mediterranean vole: An example. Acta theriol., 29, 10: 141-143 [With 2 Tables \& 1 Fig.]

A simple and inexpensive live trap for capturing fossorial small mammals is described. It consist of a plastic tube (dark and hard, or any other imitation material) with a swinging door at each end. The trap was either positioned along or at the end of the tunnel. The hight efficiency of capture and recapture is shown with four colonies of Mediterranean voles. Up to six traps can be constructed in 1 hour, in any place, with very common and abundant material. The price is very low.

[Unidad Ecologia y Etologia, Estación Biológica Donana, Ap. Sevilla, Espana]
\end{abstract}

\section{INTRODUCTION}

It is frequent that small mammals with subterraneous habits escape from scientific attention, because of the difficulty which arises in catching sufficient live animals in good enough health condition to carry out an extensive study of their populations (Hickman, 1979; Jensen, 1982). In general, the types of traps described or more frequently employed until now to catch live fossorial small mammals are quite complex in construction, and sometimes the price and the time necessary to build them do not correspond with the expected success and efficiency of trapping (i.e. Moore, 1940; Rudge, 1963; Airoldi, 1978; Hickman, 1979; Jensen, 1982). It is for this reason that we are describing a type of trap which is simple, effective and very low priced.

\section{DESCRIPTION OF THE TRAP}

The model described (Fig. 1) basically consists of a plastic tube (dark and hard, or any other imitation material) with a swinging door at each end. To check more easily, at any moment, that there is an animal in the trap or not, a string, at the end of which the bait is fixed, is introduced through a hole made on the top side of the tube. With this

Present address: ${ }^{1}$ Pagés del Corro 117, $3^{\circ}$ A. Sevilla. Espana. ${ }^{2}$ Cervantes 1. Cabra (Córdoba). Espana. 
system, one has only to look at the length of the string outside to know if there has been a reduction in its original length. The construction of this model with only one door resulted in a great efficiency for use at the entrances of the galleries that had previously been cleaned of earth.
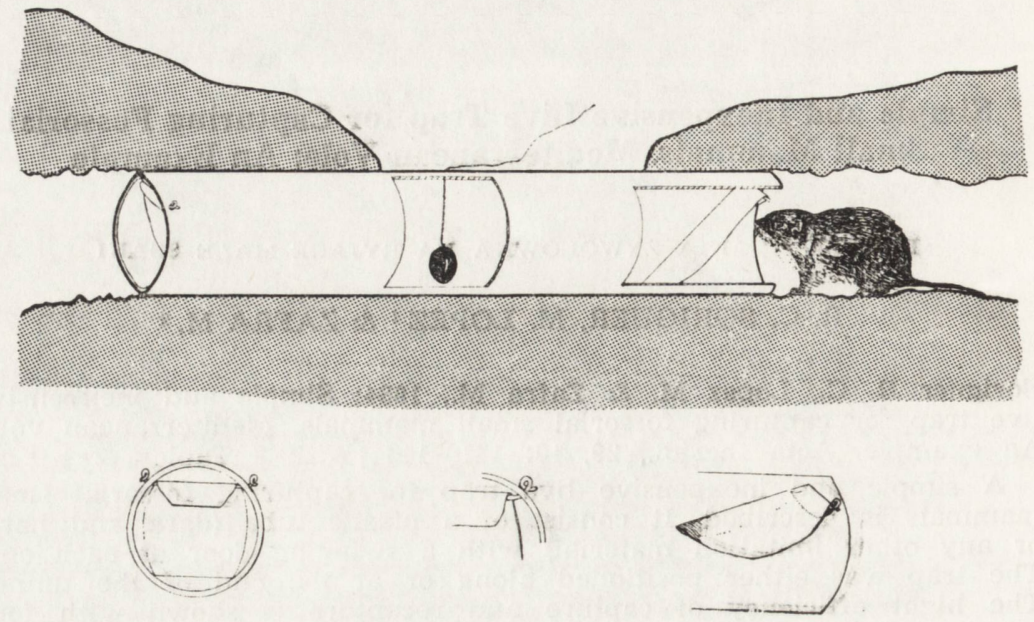

Fig. 1. Detail of trap construction and placing of a model of a live trap for capturing fossorial small mammals. The trap length is $25 \mathrm{~cm}$ and the interior diameter is $3.0 \mathrm{~cm}$. The bait used was ripe olive fruit.

\section{TRAP PLACING}

Once the fresh mounds of earth made by the voles are localized, one has to dig between two mounds until the subterranean gallery is found, leaving sufficient uncovered tunnel to be able to set the trap (at the same level) between the two ends of the piece of dugont tunnel (Fig. 1). Following this, the joints between the trap ends and the tunnel are to be covered with earth, so that the trap will substitute the section of tunnel previously dug. Likewise, it is verified that the string (used for checking the capture) stays in the correct position so that in case of

Table 1

Captures of Mediterranean Vole (Pitymys duodecimcostatus) obtained with a new model of live trap. A1 and A Mountain localities, B "Campina" (Plains) locality, Cabra (Cordoba), Andalucía, Spain.

\begin{tabular}{lccccc}
\hline Sites & $\begin{array}{c}\text { Number } \\
\text { captures }\end{array}$ & $\begin{array}{c}\text { Trapping 1,2 } \\
\text { effort, hours }\end{array}$ & $\begin{array}{c}\text { Number } \\
\text { days }\end{array}$ & Trap/day & $\begin{array}{c}\text { Number } \\
\text { burrows }\end{array}$ \\
\hline A & 11 & 8 & 2 & 4 & 4 \\
B & 41 & 17 & 10 & 3 & 2 \\
A1 & 4 & 4 & 1 & 8 & 3 \\
& 56 & 29 & 13 & 15 & 9 \\
\hline
\end{tabular}

1 No. captures/No. hour traps had been set.

2 In four occasions two voles were caught together in the same trap. 
capture, this would be detected by a variation in the length of the string which is on the outher side of the trap. The easiness of the trap placing (both models) and the versatility of the double entrance, reduces to half not only the surface of excavated tunnel, but also the number of traps needed to employ compared with other described models.

\section{EFFICIENCY OF CAPTURE}

The Table 1 sums up the number of captures, trapping effort, number of traps/day and burrows in three trapping places. It was observed that the overall capture efficiency (number of captures/hour/trap) is 0.13 , which in comparison to other models gives very elevated results. On the other hand, the effect of the capture over the behaviour of the voles

Table 2

Number of times that a Mediterranean vole had been captured (from the plots A, A1 and B). See Table 1 for more details.

\begin{tabular}{|c|c|c|c|c|c|c|}
\hline Plot & 1 & $\operatorname{Jum}_{2}$ & $\begin{array}{l}\text { of } \\
3\end{array}$ & $\begin{array}{r}\text { es } \\
4\end{array}$ & $\underset{5}{\text { captured }}$ & 6 \\
\hline A & 4 & 2 & 1 & 0 & 0 & 0 \\
\hline B & 6 & 0 & 6 & 0 & 1 & 2 \\
\hline A1 & 4 & 0 & 0 & 0 & 0 & 0 \\
\hline
\end{tabular}

seems to be of little importance as can be deduced from the high number of recaptures and by the frequent recaptures of some of them (see Table 2).

\section{CHARACTERISTICS AND COST}

The model of the trap described (Fig. 1) is of an extreme simplicity. Up to six traps can be constructed in 1 hour, in any place, with very common and abundant materials. The price is low (less than $\$ 0.10 /$ trap) or even cheaper if second hand material is used.

Acknowledgements: We thank Karen for translating the MS. P. Jordano improved the original figure considerably. This study was supported by the CAICYT Programme and by Estación Biológica de Doñana. One of the authors (R.C.S.) holds a postdoctoral fellowship of CSIC.

\section{REFERENCES}

Airoldi G. J.-P., 1978: Etude par capture et recapture d'une population des campagnols terrestres Arvicola terrestris sherman Shaw (Mammalia, Rodentia). Terre et Vie, 32: 3-45. - Hickman G. C., 1979: A live trap and trapping technique for fossorial mammals. South Afr. J. Zool., 14: 9-12. - Jensen I., 1982: A new live-trap for moles. J. Wild. Manage., 46: 249-252. - Moore A. W., 1940: A live: mole trap. J. Mammal., 21: 223-225. - Rudge J., 1963: A study of mole trapping. Proc. Zool. Soc., Lond., 140: 330-334.

Accepted, November 15, 1983. 